\title{
REMOÇÃO DE AZUL DE METILENO DE SOLUÇÃO AQUOSA USANDO ZEÓLITAS SINTETIZADAS COM AMOSTRAS DE CINZAS DE CARVÃO DIFERENTES
}

\section{Denise Alves Fungaro* e Mariza Bruno}

Centro de Química e Meio Ambiente, Instituto de Pesquisas Energéticas e Nucleares, Av. Prof. Lineu Prestes, 2242, 05508-000

São Paulo - SP, Brasil

Recebido em 9/6/08; aceito em 29/10/08; publicado na web em 26/2/09

\begin{abstract}
REMOVAL OF METHYLENE BLUE FROM AQUEOUS SOLUTION USING ZEOLITE SYNTHESIZED FROM DIFFERENT COAL FLY ASHES SAMPLES. Batch sorption experiments were carried out to remove methylene blue from its aqueous solutions using zeolites synthesized from fly ashes as an adsorbent. The adsorbents were characterized by XFR, XRD and SEM. Nearly 90 min of contact time are found to be sufficient for the adsorption of dye to reach equilibrium. Equilibrium data have been analyzed using Langmuir and Freundlich isotherms and the results were found to be well represented by the Freundlich isotherm equation. Adsorption data were fitted to both Lagergren first-order and pseudo-second-order kinetic models and the data were found to follow pseudo-second-order kinetics.
\end{abstract}

Keywords: zeolite; methylene blue; dye adsorption.

\section{INTRODUÇÃO}

Um dos principais problemas ambientais causados por usinas termelétricas é derivado da produção de toneladas de cinzas de carvão no processo de geração de energia elétrica. Estima-se que cerca de 4 milhões de $\mathrm{t}$ de cinzas de carvão foram produzidas no país em 2005 e este número tende a aumentar devido à demanda de energia elétrica pela sociedade.

A forma de acumulação destas cinzas se dá numa decisão puramente econômica, sem considerar as relações com o meio ambiente, sendo dispostas de forma inadequada dentro do perímetro urbano e nas zonas rurais. A disposição das cinzas em aterros oferece perigos potenciais aos mananciais hídricos, pois contaminam as águas superficiais, as águas subterrâneas e o solo, pela lixiviação das substâncias tóxicas presentes em suas partículas. Estudos recentes demonstraram que as cinzas de carvão provenientes da região sul do Brasil continham altos teores dos elementos $\mathrm{As}, \mathrm{U}, \mathrm{Mo}, \mathrm{Hg}, \mathrm{Pb}$ e $\mathrm{Cd}$ que foram facilmente lixiviados pela água. ${ }^{1}$

A principal aplicação das cinzas de carvão é a comercialização para o setor de construção, mas isto ainda ocorre em pequena escala e em apenas algumas centrais termelétricas do Brasil ( 34\% da cinza gerada). ${ }^{2} \mathrm{O}$ pequeno nível de consumo das cinzas de carvão é inevitável, devido à combinação de custos altos de transporte com produto de relativamente baixo valor no mercado.

O principal esforço no sentido de mitigar os impactos ambientais decorrentes da disposição destes resíduos no meio ambiente é dirigido no sentido de ampliar as potencialidades de utilização, em particular, com a transformação das cinzas de carvão em um produto de alto valor agregado. Kumar et al. ${ }^{3}$ apresentaram uma revisão sobre o desenvolvimento e a aplicação de produtos de cinzas de carvão de valor agregado.

A similaridade na composição química da cinza de carvão com o material vulcânico precursor de zeólitas naturais foi a principal razão do desenvolvimento de experimentos envolvendo a síntese de zeólitas a partir desta matéria-prima. Embora o potencial de aplicação do produto sintetizado possa consumir somente uma porção pequena

*e-mail: dfungaro@ipen.br das cinzas de carvão geradas em usinas termelétricas, os produtos finais obtidos alcançam, relativamente, um maior valor agregado que aquele de uso comum na construção civil.

Todas as metodologias desenvolvidas para sintetizar zeólitas a partir de cinza de carvão estão baseadas na dissolução das fases sustentadas por $\mathrm{Si}$ e $\mathrm{Al}$ com soluções alcalinas (principalmente soluções de $\mathrm{NaOH}$ e $\mathrm{KOH}$ ) em diferentes condições de temperatura, pressão e tempo de reação. Após esta etapa, ocorre a subseqüente precipitação do material zeolítico. ${ }^{4} \mathrm{~A}$ cristalização em um estágio resulta, geralmente, em um material zeolítico que contém 20-75\% de zeólita, dependendo das condições da reação de ativação e cinza de carvão não-convertida. As substâncias tóxicas que a cinza contém são removidas na solução básica, que é encaminhada para tratamento e/ou reaproveitamento posterior.

As zeólitas são aluminossilicatos hidratados de metais alcalinos e alcalinos terrosos (principalmente $\mathrm{Na}, \mathrm{K}, \mathrm{Mg}$ e $\mathrm{Ca}$ ), estruturados em redes cristalinas tridimensionais, compostas de tetraedros do tipo $\mathrm{TO}_{4}$ ( $\mathrm{T}=\mathrm{Si}, \mathrm{Al}, \mathrm{Ga}, \mathrm{Ge}, \mathrm{Fe}, \mathrm{B}, \mathrm{P}, \mathrm{Ti}$, etc) unidos nos vértices através de átomos de oxigênio. ${ }^{5-7}$ A estrutura da zeólita apresenta canais e cavidades interconectadas de dimensões moleculares, nas quais se encontram íons de compensação, moléculas de água ou outros adsorbatos e sais. Este tipo de estrutura microporosa confere à zeólita uma superfície interna muito grande, quando comparada à sua superfície externa, apresentando as propriedades de adsorção, capacidade de troca iônica e catálise.

Desde os estudos iniciais por Höller e Wirsching, ${ }^{8}$ muitos pesquisadores têm proposto métodos de ativação hidrotérmica para sintetizar zeólitas a partir de cinza de carvão. O método mais comum é a conversão clássica alcalina com hidróxido de sódio. ${ }^{8-14}$ Recentemente, métodos de ativação hidrotérmica envolvendo fusão ${ }^{15-17}$ e usando microndas ${ }^{18,19}$ foram investigados visando melhorar a conversão.

Os principais fatores que influenciam a síntese de zeólitas a partir de cinzas de carvão são: a amostra de cinzas de carvão; o tipo e a concentração do meio reacional; a pressão; a temperatura; o tempo de reação; a relação volume de solução alcalina/massa de cinzas e o uso de promotores (sementes, direcionadores).

Em relação às cinzas de carvão, estas vão mostrar variação em sua composição e nas propriedades físico-químicas, não só de usina para usina, mas de caldeira para caldeira na mesma usina e até numa 
mesma caldeira em tempos diferentes. Artigos da literatura relatam que vários tipos de zeólitas podem ser obtidos pela mudança da amostra de cinzas de carvão usada como matéria-prima. ${ }^{9,13,20}$ Cada tipo de zeólita irá apresentar propriedades de adsorção características.

Uma das principais aplicações da zeólita de cinzas de carvão tem sido na remoção de íons metálicos e do íon amônio em água, devido a sua alta capacidade de troca catiônica. ${ }^{11,12,21-29}$ Estudos sobre esta alternativa em relação à remoção de corantes em água são mais escassos. ${ }^{30-34}$

Os corantes são visualmente detectáveis e causam sérios problemas de natureza estética nos corpos d'água receptores, mesmo quando presentes em pequenas quantidades. Além disso, a maioria dos corantes é resistente à biodegradação, à fotodegradação e à ação de agentes oxidantes e alguns são suspeitos de induzirem efeitos carcinogênicos e/ou mutagênicos. ${ }^{35,36}$

Entre vários tipos de tratamento, ${ }^{37} \mathrm{a}$ adsorção utilizando materiais adsorventes de baixo custo tem despertado crescente interesse como técnica para remoção de corantes em solução aquosa e, para este fim, diversos resíduos orgânicos e industriais têm sido testados. ${ }^{38,39}$

O objetivo do trabalho foi avaliar a eficiência de adsorção do azul de metileno em zeólitas sintetizadas a partir de amostras de cinzas de carvão diferentes submetidas às mesmas condições de tratamento hidrotérmico.

\section{PARTE EXPERIMENTAL}

\section{Materiais}

Todos os reagentes usados foram de grau analítico. As soluções do azul de metileno foram preparadas a partir da diluição de solução estoque com água ultrapura do sistema Millipore Milli-Q.

As cinzas de carvão geradas na Usina Termelétrica de Figueira, localizada no Paraná, foram utilizadas neste estudo. As cinzas leves de carvão retidas no filtro manga foram amostradas num período de 10 meses em intervalos de 2 meses, perfazendo um total de 5 lotes de cinzas. As zeólitas das cinzas do filtro manga (ZM) com números de 1 a 5 referem-se ao material coletado nas 5 amostragens.

\section{Preparação das zeólitas por síntese hidrotérmica}

A amostra contendo $30 \mathrm{~g}$ de cinzas de carvão foi colocada com $240 \mathrm{~mL}$ de $\mathrm{NaOH}$ 3,5 mol L-1 (relação cinzas/solução $0,125 \mathrm{~g} \mathrm{~mL}^{-1}$ ) e aquecida em estufa, à $100{ }^{\circ} \mathrm{C}$, por $24 \mathrm{~h}$. A suspensão foi filtrada e o sólido foi repetidamente lavado com água deionizada até $\mathrm{pH} \sim 10$ e seco em estufa a $50^{\circ} \mathrm{C}$.

\section{Estudos sobre a remoção do corante}

A remoção do azul de metileno em solução aquosa pelas zeólitas foi realizada por processos descontínuos. Uma alíquota de $100 \mathrm{~mL}$ de solução do corante de concentração conhecida (faixa de 1,6 a 32 $\mathrm{mg} \mathrm{L}^{-1}$ ) foi colocada em um béquer com $1 \mathrm{~g}$ de zeólita e agitada com agitador mecânico, com temperatura controlada, a 120 rpm. Após um tempo de contato desejado, o sobrenadante foi separado por centrifugação e a concentração final nesta solução foi determinada.

A concentração do corante azul de metileno foi determinada por espectrofotometria UV-Visível (espectrofotômetro modelo Cary 1E da Varian), no comprimento de onda correspondente à absorbância máxima, $\lambda_{\max }=650 \mathrm{~nm}$. A capacidade de adsorção do adsorvente (q em $\mathrm{mg} \mathrm{g}^{-1}$ ) foi calculada conforme a Equação:

$\mathrm{q}=\frac{\mathrm{V}\left(\mathrm{C}_{0}-\mathrm{C}_{\mathrm{f}}\right)}{\mathrm{M}}$ onde $\mathrm{V}(\mathrm{L})$ é o volume da solução de corante, $\mathrm{C}_{\mathrm{o}}\left(\mathrm{mg} \mathrm{L}^{-1}\right)$ é a concentração inicial da solução de corante, $\mathrm{C}_{\mathrm{f}}\left(\mathrm{mg} \mathrm{L}^{-1}\right)$ é a concentração final da solução de corante obtida após um tempo t e M (g) é a massa de zeólita. O tempo de equilíbrio utilizado para obtenção das isotermas foi determinado a partir dos estudos cinéticos.

\section{Caracterização das zeólitas de cinzas de carvão}

A composição química foi determinada por fluorescência de raios-X, em equipamento Rigaku RIX-3000. A composição mineralógica foi obtida por difração de raios-X no equipamento Rigaku, modelo Multiflex, gerada a $40 \mathrm{kV}$ e $20 \mathrm{~mA}$ usando radiação de $\mathrm{Cu}-\mathrm{K} \alpha(\lambda=1,54060 \AA)$. A velocidade angular foi de $1 \%$ min e o intervalo de varredura foi de $2 \theta=5$ a $80^{\circ}$. A microscopia eletrônica de varredura (MEV) foi realizada utilizando o equipamento XL 30 da Philips para verificar a morfologia e o tamanho dos cristais. As amostras foram previamente metalizadas com uma fina camada de ouro. A superfície específica BET foi determinada pelo equipamento BET Surface Área Analyser - Versão 3.11 - Quanta-Chrome Corporation - Nova 1200. Primeiramente, a amostra foi desgaseificada por $12 \mathrm{~h}$ em banho de areia a $150{ }^{\circ} \mathrm{C}$ para retirada de voláteis e gases interferentes; em seguida, houve adsorção de nitrogênio para garantir a atmosfera inerte e, finalmente, a determinação foi feita por meio da adsorção e dessorção de nitrogênio nas amostras em condições de vácuo de $0,1 \mathrm{~mm} \mathrm{Hg}$. A massa específica das zeólitas foi determinada via pictometria de hélio de pós sinterizados de $\mathrm{U}_{3} \mathrm{O}_{8}, \mathrm{U}_{3} \mathrm{Si}_{2}$ e de $\mathrm{Al}$ (Pictômetro Micromeritcs - Accupyc 1330). ${ }^{40}$

\section{RESULTADOS E DISCUSSÃO}

\section{Caracterização dos materiais adsorventes}

A Tabela 1 apresenta a composição química (em \% em massa) determinada por fluorescência de raios-X de todas as zeólitas de cinzas de carvão utilizadas no estudo.

Tabela 1. Composição química das zeólitas sintetizadas a partir de cinzas de carvão

\begin{tabular}{lccccc}
\hline $\begin{array}{l}\text { Óxidos } \\
(\% \text { em massa })\end{array}$ & $\mathrm{ZM} 1$ & $\mathrm{ZM} 2$ & $\mathrm{ZM} 3$ & $\mathrm{ZM} 4$ & $\mathrm{ZM} 5$ \\
\hline $\mathrm{SiO}_{2}$ & 40,91 & 43,95 & 43,41 & 39,54 & 36,29 \\
$\mathrm{Al}_{2} \mathrm{O}_{3}$ & 24,38 & 21,90 & 22,39 & 27,87 & 29,06 \\
$\mathrm{Fe}_{2} \mathrm{O}_{3}$ & 11,72 & 12,83 & 13,26 & 11,10 & 10,05 \\
$\mathrm{Na}_{2} \mathrm{O}$ & 10,87 & 7,51 & 8,52 & 13,92 & 15,90 \\
$\mathrm{CaO}$ & 5,03 & 5,19 & 4,41 & 1,91 & 1,67 \\
$\mathrm{~K}_{2} \mathrm{O}$ & 2,31 & 3,91 & 2,56 & 0,67 & 0,60 \\
$\mathrm{TiO}_{2}$ & 1,60 & 1,50 & 1,44 & 1,38 & 1,45 \\
$\mathrm{SO}_{3}$ & 1,26 & 1,65 & 2,21 & 1,33 & 2,63 \\
$\mathrm{MgO}$ & 1,07 & 0,91 & 0,88 & 1,29 & 1,15 \\
$\mathrm{ZnO}_{\mathrm{ZrO}}$ & 0,30 & 0,26 & 0,30 & 0,36 & 0,31 \\
$\mathrm{PbO}$ & 0,17 & 0,12 & 0,21 & 0,17 & 0,22 \\
$\mathrm{SrO}$ & - & - & 0,14 & - & 0,12 \\
$\mathrm{P}_{2} \mathrm{O}_{5}$ & - & - & - & - & 0,14 \\
$\mathrm{SiO}_{2} / \mathrm{Al}_{2} \mathrm{O}_{3}$ & 1,68 & 2,01 & 1,94 & 1,42 & 1,25 \\
\hline
\end{tabular}


As zeólitas de cinzas de carvão constituíam-se principalmente de alumina e sílica (22-44\%) e conteúdos baixos de óxido férrico (10-13\%) e óxidos de cálcio (2- 5\%). Encontraram-se os óxidos de potássio, titânio, enxofre, magnésio e outros compostos em quantidades menores que $4 \%$. O conteúdo de $\mathrm{Na}_{2} \mathrm{O}$ passou da faixa de $0,98-1,2 \%$ encontrada nas cinzas para 7,5-15,9\% nas respectivas zeólitas. Este aumento pode ser atribuído ao uso de solução concentrada de $\mathrm{NaOH}$ no processo de conversão em zeólita.

A área superficial específica BET e as massas específicas das zeólitas de cinzas de carvão foram determinadas pelas isotermas de adsorção de nitrogênio (Tabela 2). A área superficial BET apresentou valores entre $53,4 \mathrm{a} 90,7 \mathrm{~m}^{2} / \mathrm{g}$. Estes valores eram pelo menos 5 vezes maiores que o das respectivas cinzas usadas como matéria-prima devido à cristalização das zeólitas sobre as partículas esféricas lisas das cinzas.

Tabela 2. Massa específica e área superficial específica das zeólitas sintetizadas a partir de cinzas de carvão

\begin{tabular}{lcc}
\hline Zeólitas & Massa Específica $\left(\mathrm{g} / \mathrm{cm}^{3}\right)$ & Área Superficial $\left(\mathrm{m}^{2} / \mathrm{g}\right)$ \\
\hline ZM1 & 2,51 & 69,3 \\
ZM2 & 2,54 & 53,4 \\
ZM3 & 2,44 & 86,4 \\
ZM4 & 2,41 & 81,2 \\
ZM5 & 2,42 & 90,7 \\
\hline
\end{tabular}

A Figura 1 apresenta um difratograma de raios-X para a zeólita de cinzas de carvão ZM1. O estudo revelou a formação preferencial da zeólita Na-P1 após o tratamento hidrotérmico alcalino juntamente com hidroxissodalita. Quartzo e mulita são provenientes das cinzas que não reagiram no tratamento hidrotérmico e fazem parte do material zeolítico. Os difratogramas das zeólitas ZM2 a ZM5 (não apresentados) são similares ao da zeólita ZM1.

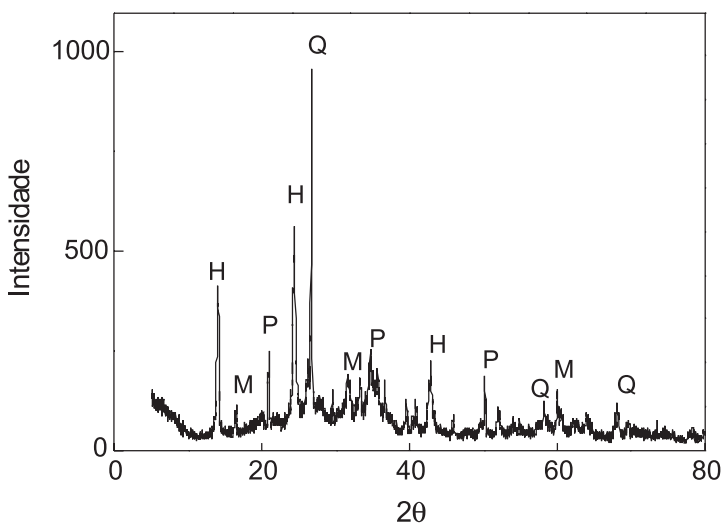

Figura 1. Difratograma da zeólita sintetizada a partir de cinzas de carvão ZM1. $Q=$ Quartzo; $M=$ Mulita $H=$ hidroxisodalita $P=N a-P 1$

A micrografia MEV da zeólita de cinzas de carvão ZM1 está apresentada na Figura 2 e das zeólitas ZM2 a ZM5 na Figura 1S (Material Suplementar). Pode-se observar em cada material que a superfície é rugosa, apresentando aglomerados de partículas pequenas porque os cristais de zeólita precipitam sobre as partículas das cinzas de carvão durante o tratamento alcalino. A maioria dos cristalitos é pequena devido à presença de impurezas nas cinzas de carvão, que levam a uma nucleação rápida prejudicando o crescimento do cristal. ${ }^{41}$

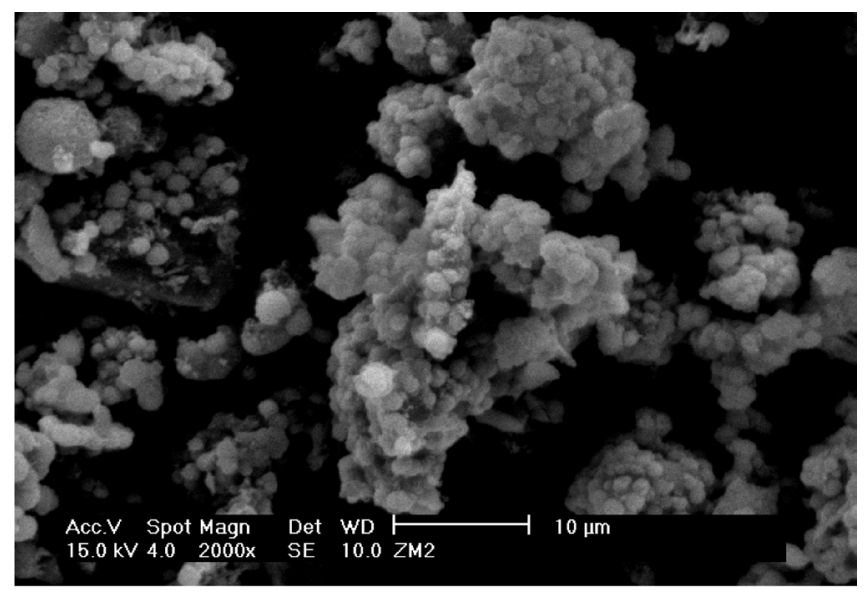

Figura 2. Fotograma MEV da zeólita de cinzas de carvão ZM1

Estudos da adsorção do corante sobre as zeólitas de cinzas de carvão

\section{Efeito de tempo de contato}

Os efeitos do tempo de agitação e da concentração inicial na adsorção do azul de metileno pela zeólita ZM1(Figura 3) e pela zeólitas ZM2 a ZM5 (Figura 2S - Material Suplementar) foram investigados A quantidade de corante adsorvida pelo adsorvente $\left(\mathrm{mg} \mathrm{g}^{-1}\right)$ aumentou com o tempo de agitação e com o aumento da concentração inicial do corante. O tempo de equilíbrio foi de $\sim 90$ min para todos os adsorventes e a eficiência de adsorção estava entre 43 a 90\%. O aumento da concentração inicial do corante proveu uma força que superou a resistência à transferência de massa entre a fase aquosa e a fase sólida, a qual possuía sítios ativos de adsorção disponíveis para a faixa de concentração do corante estudada.

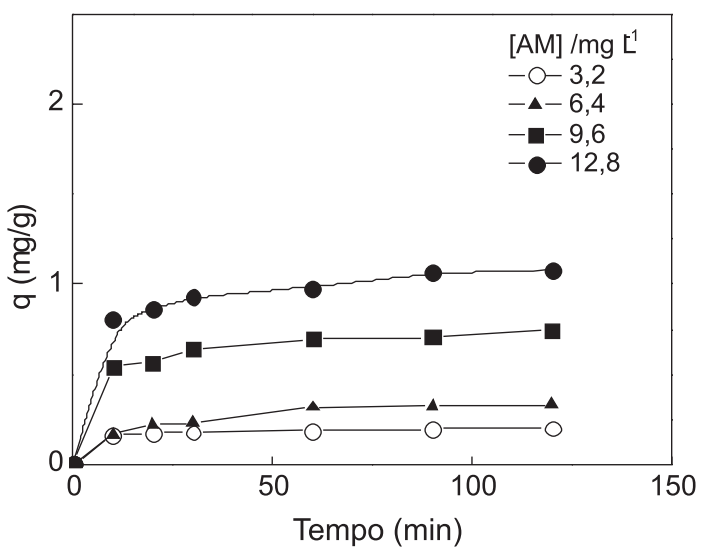

Figura 3. Efeito do tempo de agitação e da concentração do azul de metileno sobre a capacidade de adsorção da zeólita de cinzas de carvão ZM1

\section{Isotermas de adsorção}

A Figura 4 mostra a isoterma de adsorção do azul de metileno sobre a zeólita ZM1 obtida após 90 min de agitação, onde $\mathrm{C}_{\mathrm{e}}\left(\mathrm{mg} \mathrm{L}^{-1}\right)$ corresponde à concentração de equilíbrio do corante na fase líquida e $\mathrm{q}_{\mathrm{e}}\left(\mathrm{mg} \mathrm{g}^{-1}\right)$ é a capacidade de adsorção do adsorvente. As isotermas de adsorção das zeólitas ZM2 a ZM5 podem ser vistas na Figura 3S (Material Suplementar).

As isotermas de sistemas líquido/sólido podem ser classificadas de acordo com suas formas que são determinadas pelo mecanismo de adsorção e, portanto, esta classificação pode ser usada para o diagnóstico da natureza da adsorção. ${ }^{42}$ As isotermas de equilíbrio 


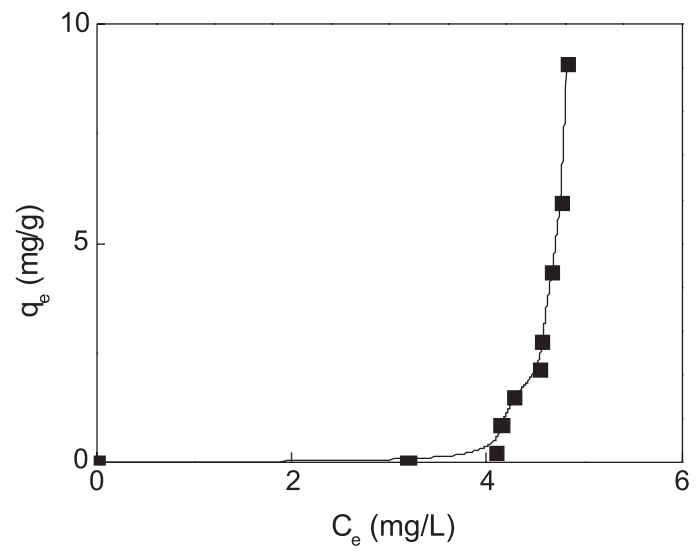

Figura 4. Isoterma de adsorção do azul de metileno sobre a zeólita de cinzas de carvão $Z M 1$

das zeólitas ZM1 a ZM5 apresentaram curvas na forma sigmoidal com comportamento correspondente à isoterma Tipo S3, indicando a formação de multicamada e adsorção cooperativa. ${ }^{42}$

Os dados de adsorção foram analisados usando-se os modelos de Langmuir e Freundlich que são os mais freqüentemente usados para descrever isotermas para aplicações em tratamento de águas e efluentes. ${ }^{43,44}$

Os parâmetros das isotermas de Langmuir e Freundlich foram determinados por regressão linear das equações linearizadas. Os dados não se ajustaram ao modelo de adsorção de Langmuir, apresentando valores das constantes negativos. Este fato sugere que o comportamento do processo de adsorção não segue as proposições nas quais o modelo de Langmuir foi baseado, ou seja, a formação de uma monocamada do adsorbato na superfície do adsorvente envolvendo energias uniformes de adsorção. O material zeolítico contém diversos óxidos que conferem a sua superfície sítios ativos com características diferentes e esta heterogeneidade influencia a adsorção. As constantes de Freundlich estão listadas na Tabela 3. Os dados experimentais ajustaram-se ao modelo da isoterma de Freundlich evidenciado pelos valores do coeficiente de correlação $(\mathrm{R}>0,90)$ para as zeólitas ZM1 a ZM5. O valor da constante $\mathrm{n}$ menor que 1 indicou que no sistema azul de metileno/zeólita ocorre processo de adsorção cooperativa em sítios ativos do adsorvente com energias diferentes de ligação. ${ }^{45,46} \mathrm{Na}$ adsorção cooperativa, há uma interação entre as espécies do adsorbato que favorece a adsorção na superfície do adsorvente, já que o adsorbato tem dificuldade de acesso aos poros do adsorvente.

Tabela 3. Parâmetros do modelo de Freundlich para a adsorção do azul de metileno sobre as zeólitas sintetizadas a partir de cinzas de carvão

\begin{tabular}{lccc}
\hline Zeólitas & \multicolumn{3}{c}{ Freundlich } \\
& $\mathrm{K}_{\mathrm{f}}^{*}$ & $\mathrm{n}$ & $\mathrm{R}^{2}$ \\
\hline ZM1 & $3,8 \times 10^{-15}$ & 0,044 & 0,987 \\
ZM2 & $2,1 \times 10^{-3}$ & 0,21 & 0,933 \\
ZM3 & $1,9 \times 10^{-5}$ & 0,13 & 0,964 \\
ZM4 & $4,4 \times 10^{-8}$ & 0,077 & 0,902 \\
ZM5 & 0,78 & 0,13 & 0,968 \\
\hline
\end{tabular}

$(*)\left(\mathrm{mg} \mathrm{g}^{-1}\right)\left(\mathrm{L} \mathrm{mg}^{-1}\right)^{1 / \mathrm{n}}$

A capacidade de adsorção das zeólitas decresceu na seguinte ordem: ZM5 > ZM2 > ZM3 > ZM4 > ZM1. Esta eficiência de adsorção está relacionada com a menor relação $\mathrm{SiO}_{2} / \mathrm{Al}_{2} \mathrm{O}_{3}$ da ZM5
(Tabela 1) e, consequientemente, maior capacidade de troca iônica ${ }^{5}$ e também com outros fatores, como a área superficial específica. O desempenho da adsorção do azul de metileno sobre as cinzas de carvão, matérias-primas das zeólitas, também foi estudado para comparação. Observaram-se capacidades de adsorção máxima pelo menos 8 vezes menores que os valores obtidos com as respectivas zeólitas e uma saturação do material mais rápida. Zeólitas de cinzas de carvão amostradas na Austrália apresentaram valores de capacidade de adsorção do azul de metileno entre 1,42 e 1,92 $\left(\mathrm{mg} \mathrm{g}^{-1}\right)(\mathrm{L} \mathrm{mg})^{-1 / n}$. As zeólitas foram sintetizadas por tratamento hidrotérmico alcalino com parâmetros diferentes aos usados neste trabalho. ${ }^{30,32}$

\section{Modelos cinéticos de adsorção}

O comportamento transiente do processo de adsorção do azul de metileno pelos adsorventes foi analisado usando os modelos cinéticos de pseudo-primeira ordem de Lagergren, ${ }^{47}$ pseudo-segunda ordem de Ho e Mckay ${ }^{48}$ e modelo da difusão intrapartícula. ${ }^{49} \mathrm{~A}$ validade destes modelos pode ser avaliada pelos gráficos lineares de cada equação: $\log \left(\mathrm{q}_{\mathrm{e}}-\mathrm{q}_{\mathrm{t}}\right)$ vs $\mathrm{t}$ para o modelo da pseudo-primeira ordem, $\mathrm{t} / \mathrm{q}_{\mathrm{t}} v s \mathrm{t}$ para o modelo de pseudo-segunda ordem e $\mathrm{q}_{\mathrm{t}} v s \mathrm{t}^{1 / 2}$ para a difusão intrapartícula.

Os parâmetros cinéticos do processo de adsorção do azul de metileno sobre a zeólita ZM1 foram obtidos pelas regressões lineares dos gráficos de cada modelo (Tabela 4). Os mesmos parâmetros foram também obtidos para as demais zeólitas (não apresentados). A avaliação quantitativa dos modelos foi realizada pela comparação dos coeficientes de correlação. Os resultados mostraram que o processo de adsorção se ajustou melhor ao mecanismo de pseudo-segunda ordem para todos os adsorventes e, conseqüentemente, no controle da velocidade deve estar envolvido um mecanismo de adsorção ativado ou quimissorção. ${ }^{50} \mathrm{~A}$ linearidade observada em todos os gráficos q $v s$ $\mathrm{t}^{0,5}$, bem como o desvio das linhas da origem apontaram a presença da

Tabela 4. Parâmetros cinéticos para a adsorção do azul de metileno sobre a zeólita sintetizada a partir de cinzas de carvão ZM1

\begin{tabular}{|c|c|c|c|c|}
\hline \multirow{2}{*}{$\begin{array}{c}{[\mathrm{AM}]} \\
(\mathrm{mg} / \mathrm{L})\end{array}$} & \multicolumn{2}{|c|}{ Pseudo $-1^{\mathrm{a}}$ ordem } & & \\
\hline & $\begin{array}{c}\mathrm{K}_{1} \times 10^{-2} \\
\left(\min ^{-1}\right)\end{array}$ & $\mathrm{R}_{1}^{2}$ & & \\
\hline 3,2 & 2,28 & 0,962 & & \\
\hline 6,4 & 4,39 & 0,987 & & \\
\hline 9,6 & 2,12 & 0,970 & & \\
\hline \multirow[t]{3}{*}{12,8} & 1,94 & 0,980 & & \\
\hline & \multicolumn{2}{|c|}{ Pseudo - 2a ordem } & & \\
\hline & $\begin{array}{c}\mathrm{K}_{2} \times 10^{-1} \\
(\mathrm{~g} / \mathrm{mg} \min )\end{array}$ & $\begin{array}{c}\mathrm{h} \times 10^{-2} \\
(\mathrm{mg} / \mathrm{g} \min )\end{array}$ & $\begin{array}{l}\mathrm{q}_{\mathrm{e}} \times 10^{-1} \\
(\mathrm{mg} / \mathrm{g})\end{array}$ & $\mathrm{R}_{2}^{2}$ \\
\hline 3,2 & 15,9 & 6,41 & 2,00 & 0,999 \\
\hline 6,4 & 1,80 & 2,59 & 3,79 & 0,997 \\
\hline 9,6 & 2,72 & 15,1 & 7,44 & 0,999 \\
\hline \multirow[t]{3}{*}{12,8} & 1,68 & 20,6 & 11,1 & 0,999 \\
\hline & \multicolumn{2}{|c|}{ Difusão intrapartícula } & & \\
\hline & $\begin{array}{c}\mathrm{K}_{\mathrm{i}} \times 10^{-2} \\
\left(\mathrm{mg} / \mathrm{g} \min ^{0,5}\right)\end{array}$ & $\mathrm{R}_{\mathrm{i}}^{2}$ & & \\
\hline 3,2 & 0,468 & 0,976 & & \\
\hline 6,4 & 2,56 & 0,976 & & \\
\hline 9,6 & 2,79 & 0,961 & & \\
\hline 12,8 & 3,98 & 0,985 & & \\
\hline
\end{tabular}


difusão intrapartícula como uma etapa não determinante da velocidade do processo de adsorção do sistema azul de metileno/zeólitas. ${ }^{49}$ Resultados similares foram obtidos com os estudos cinéticos do processo de adsorção do azul de metileno sobre zeólitas de cinzas de carvão amostradas na Austrália. ${ }^{31}$

\section{CONCLUSÃO}

As amostras de cinzas de carvão de 5 amostragens foram submetidas ao mesmo tratamento hidrotérmico alcalino. Os produtos zeolíticos obtidos foram caracterizados e usados como adsorventes para a remoção do corante azul de metileno de solução aquosa. O comportamento cinético do processo de adsorção do azul de metileno foi similar para todos os adsorventes. As capacidades de adsorção foram afetadas pela concentração inicial do corante. A remoção aumentou com o aumento da concentração inicial do corante. O tempo de equilíbrio foi de $90 \mathrm{~min}$ e o processo de adsorção seguiu a cinética de pseudo-segunda ordem. A difusão intrapartícula foi uma etapa não determinante da velocidade do processo de adsorção. As isotermas de equilíbrio das zeólitas ajustaram-se ao modelo da isoterma de Freundlich, apresentando eficiência de adsorção de até 98,5\%. O estudo mostrou que zeólitas sintetizadas a partir de cinzas de carvão podem ser efetivamente usadas como adsorvente para a remoção de azul de metileno de solução aquosa.

\section{MATERIAL SUPLEMENTAR}

No material suplementar, disponível gratuitamente em http:// quimicanova.sbq.org.br na forma de arquivo PDF, encontram-se as seguintes figuras: Fotogramas MEV das zeólitas de cinzas de carvão ZM2 a ZM5 (Figura 1S); Efeito do tempo de agitação e da concentração do azul de metileno sobre a capacidade de adsorção das zeólitas ZM2 a ZM5 (Figura 2S); Isotermas de adsorção do azul de metileno sobre as zeólitas ZM2 a ZM5 (Figura 3S).

\section{AGRADECIMENTOS}

Ao Conselho Nacional de Desenvolvimento Científico e Tecnológico - CNPq e à Carbonífera do Cambuí Ltda.

\section{REFERÊNCIAS}

1. Depoi, F. S.; Pozebon, D.; Kalkreuth, W. D.; Burguer, T. S.; Resumos da $30^{a}$ Reunião Anual da Sociedade Brasileira de Química, Águas de Lindóia, Brasil, 2007.

2. Chies, F.; Warpechowski, N. I.; Zwonok, O. Em Utilização de Resíduos na Construção Habitacional; Rocha, J. C.; John, V. M., eds.; Coletânea Habitare ANTAC: Porto Alegre, 2003, cap. 7.

3. Kumar, R.; Kumar, S.; Mehrotra, S. P.; Resour. Conserv. Recycl. 2007, 52, 157.

4. Murayama, N.; Yamamoto, H.; Shibata, J.; Int. J. Miner. Process 2002 , $64,1$.

5. Breck, D. W.; Zeolite Molecular Sieves, Wiley: New York, 1974.

6. Dyer, A.; An Introduction to Zeolite Molecular Sieves, JohnWiley \& Sons: Chichester, 1988.

7. van Bekkum, H.; Flanigen, E. M.; Jansen, J. C.; Introduction to Zeolite Science and Practice, Elsevier: Amsterdam, 1991.

8. Holler, H.; Wirsching, U.; Fortschr. Miner. 1985, 63, 21.

9. Henmi, T.; Clay Sci. 1987, 6, 277.

10. Mondragon, F.; Rincon, F.; Serra, L.; Escobar, J.; Ramirez, J.; Fernandez, J.; Fuel 1990, 69, 263.

11. Singer, A.; Berkgaut, V.; Environ. Sci. Technol. 1995, 29, 1748.
12. Amrhein, C.; Haghnia, G. H.; Kim, T. S.; Mosher, P. A.; Gagajena, R. C.; Amanios, T.; Torre, L.; Environ. Sci. Technol. 1996, 30, 735.

13. Querol, X.; Plana, F.; Alaustrey A.; López-Soler, A.; Fuel 1997, 76, 793.

14. Inada, M.; Eguchi, Y.; Enomoto, N.; Hojo, J.; Fuel 2005, 84, 299.

15. Shigemoto, N.; Hayashi, H.; Miyaura, K.; J. Mater. Sci. 1993, 28 , 4781.

16. Chang, H. L.; Shih, W. H.; Ind. Eng. Chem. Res. 2000, 39, 4185.

17. Chang, H. L.; Shih, W. H.; Ind. Eng. Chem. Res. 1998, 37, 71.

18. Querol, X.; Alastuey, A.; Lopez-Soler, A.; Plana, F.; Andrés, J. M.; Juan, R.; Ferrer, P.; Ruiz, C. R.; Environ. Sci. Technol. 1997, 31, 2527.

19. Inada, M.; Tsujimoto, H.; Eguchi, Y.; Enomoto, N.; Hojo, J.; Fuel 2005, 84, 1482.

20. Wu, D.; Sui, Y.; He, S.; Wang, X.; Li, C.; Kong, H.; J. Hazard. Mater. 2008, 155, 415.

21. Lin, C. F.; His, H. C.; Environ. Sci. Technol. 1995, 29, 1109.

22. Querol, X.; Plana, F.; Alastuey, A.; Lopez-Soler, A.; Medinaceli, A.; Valero, A.; Domingo, M. J.; Garcia-Rojo, E.; Fuel 2001, 80, 857.

23. Querol, X.; Moreno, N.; Umaña, J. C.; Alastuey A.; Hernández, E.; Lopez-Soler A.; Plana, F.; Int. J. Coal Geol. 2002, 50, 413.

24. Fungaro, D. A.; Silva, M. G.; Quim. Nova 2002, 25, 1081.

25. Fungaro, D. A.; Flues, M. S-M.; Celebroni, A. P.; Quim. Nova 2004, 27, 582.

26. Fungaro, D. A.; Izidoro, J. C. Em Água - Fonte da Vida/ Prêmio Jovem Cientista e Prêmio Jovem Cientista do Futuro; Gráfica e Editora Comunicação Impressa: Porto Alegre, 2004, p. 129.

27. Fungaro, D. A.; Izidoro, J. C.; Almeida, R. S.; Eclética Quim. 2005, 30, 31.

28. Fungaro, D. A.; Izidoro, J. C.; Quim. Nova 2006, 29, 735.

29. Izidoro, J. C.; Fungaro, D. A.; Rev. Bras. Pesq. Des. 2007, 9, 101.

30. Wang, S.; Soudi, M.; Li, L.; Zhu, Z. H.; J. Hazard Mater. 2006, B133, 243.

31. Li, L.; Wang, S.; Zhu, Z. H.; J. Colloid Interface Sci. 2006, $300,52$.

32. Wang, S. B.; Boyjoo, Y.; Choueib, A.; Stud. Surf. Sci. Catal. 2005, 158, 161.

33. Woolard, C. D.; Strong, C. R.; Erasmus, C. R.; Appl. Geochem. 2002, 17,1159 .

34. Bruno, M.; Dissertação de Mestrado, Instituto de Pesquisas Energéticas e Nucleares, Brasil, 2008.

35. Alcântara, M. R.; Daltin, D.; Quim Nova 1996, 19, 320.

36. Guaritini, C. C. I.; Zanoni, M. V. B.; Quim Nova 2000, 23, 71.

37. Bertazzoli, R.; Pelegrini, R.; Quim Nova 2002, 25, 477.

38. Namasivayam, C.; Arashi, D. J. S. E.; Chemosfere 1997, 34, 401.

39. Dallago, R. M.; Smaniotto, A.; Oliveira, L. C.; Quim Nova 2005, 28, 433.

40. Viana, M.; Jouannin, P.; Pontier, C.; Chulia, D.; Talanta 2002, 57, 583.

41. Jansen, J. C. Em The preparation of oxide molecular sieve. A. Synthesis of zeólitas; van Bekkum, H.; Flanigen, E. M.; Jacobs, P. A.; Jansen, J. C., eds.; Elsevier: Amsterdam, 2001, cap. 5.

42. Giles, C. H.; MacEwan, T. H.; Nakhwa, S. N.; Smith, D. J.; Chem. Soc. London 1960, 3973.

43. Faust; S. D.; Aly, O. M.; Adsorption Process for Water Treatment, Butterworths: London, 1987.

44. Perrich, J. R.; Actived Carbon Adsorption for Waste Water Treatment, CRC Press: Boca Raton, 1981

45. Atkins, P.; Physical Chemistry, Oxford University Press: Oxford, UK, 1970.

46. Singh, B.; Alloway, B. J.; Bochereau, J. M.; Commun. Soil Sci. Plant Anal. 2000, 31, 2775.

47. Ho, Y. S.; McKay, G.; Can. J. Chem. Eng. 1998, 76, 822.

48. Ho, Y. S.; Wase, D. A. J.; Forster, C. F.; Environ. Technol. 1996, 17, 71.

49. Weber, W. J.; Morris, J. C.; J. Sanit. Engin. Div. ASCE 1963 89, 31.

50. Ho, Y. S.; McKay, G.; Chem. Eng. J. 1998, 70, 115. 


\section{REMOÇÃO DE AZUL DE METILENO DE SOLUÇÃO AQUOSA USANDO ZEÓLITAS SINTETIZADAS COM} AMOSTRAS DE CINZAS DE CARVÃO DIFERENTES

Denise Alves Fungaro* e Mariza Bruno

Centro de Química e Meio Ambiente, Instituto de Pesquisas Energéticas e Nucleares, Av. Prof. Lineu Prestes, 2242, 05508-000 São Paulo - SP, Brasil

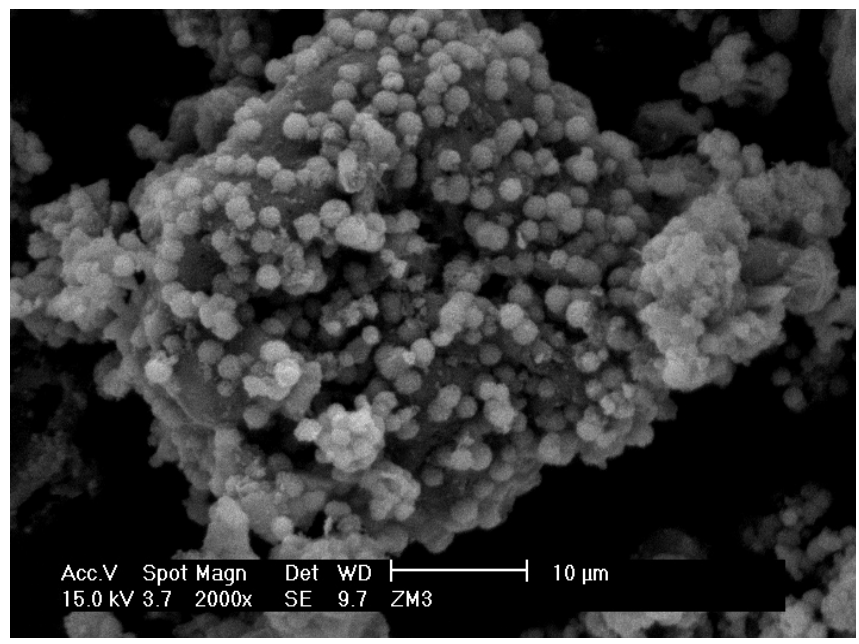

(a) ZM2

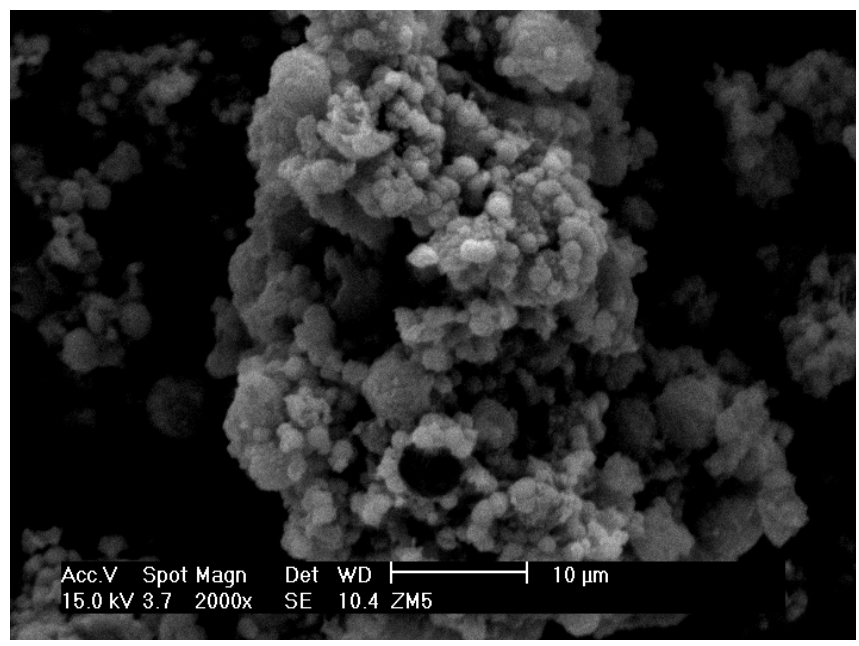

(c) ZM4

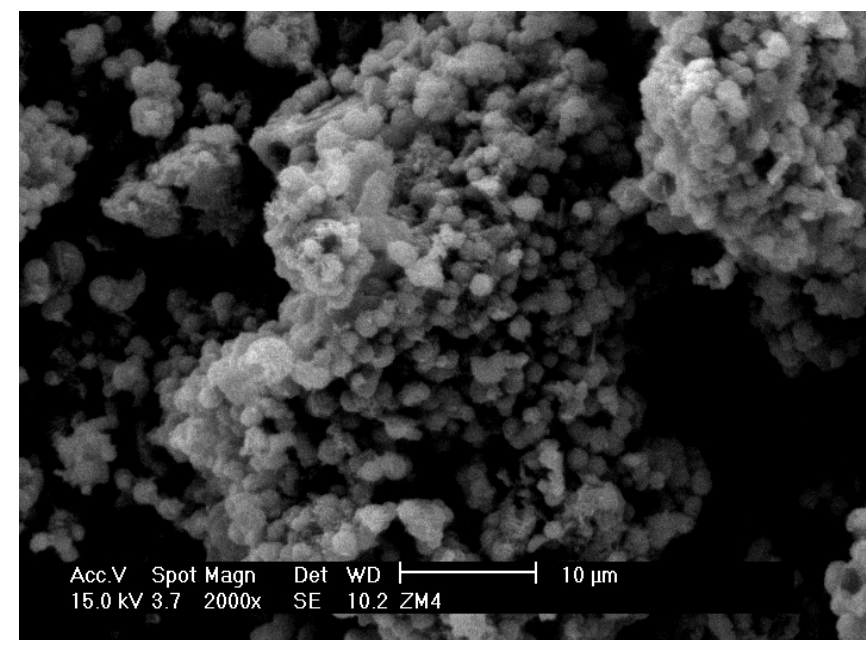

(b) ZM3

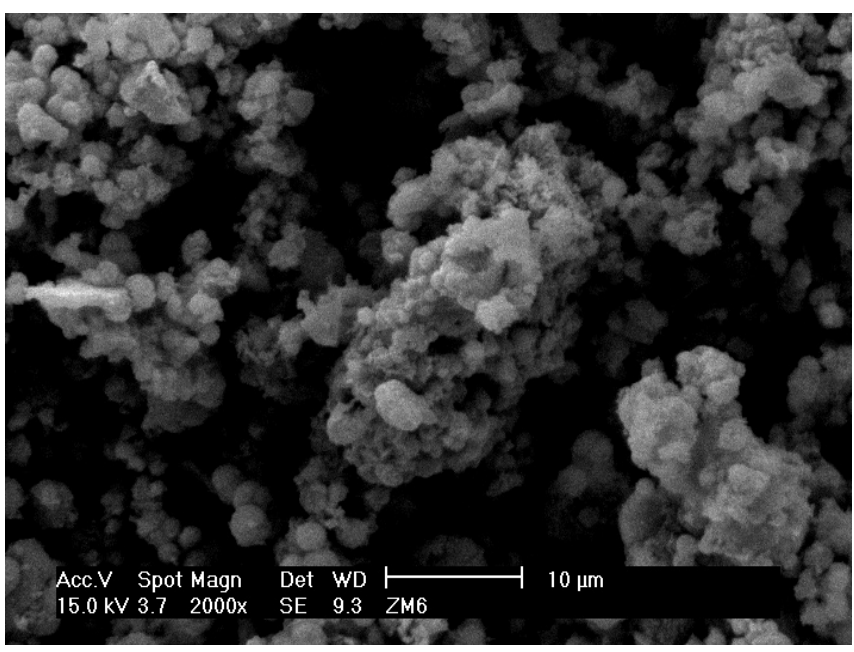

(d) ZM5

Figura 1S. Fotogramas MEV das zeólitas de cinzas de carvão ZM2 a ZM5 

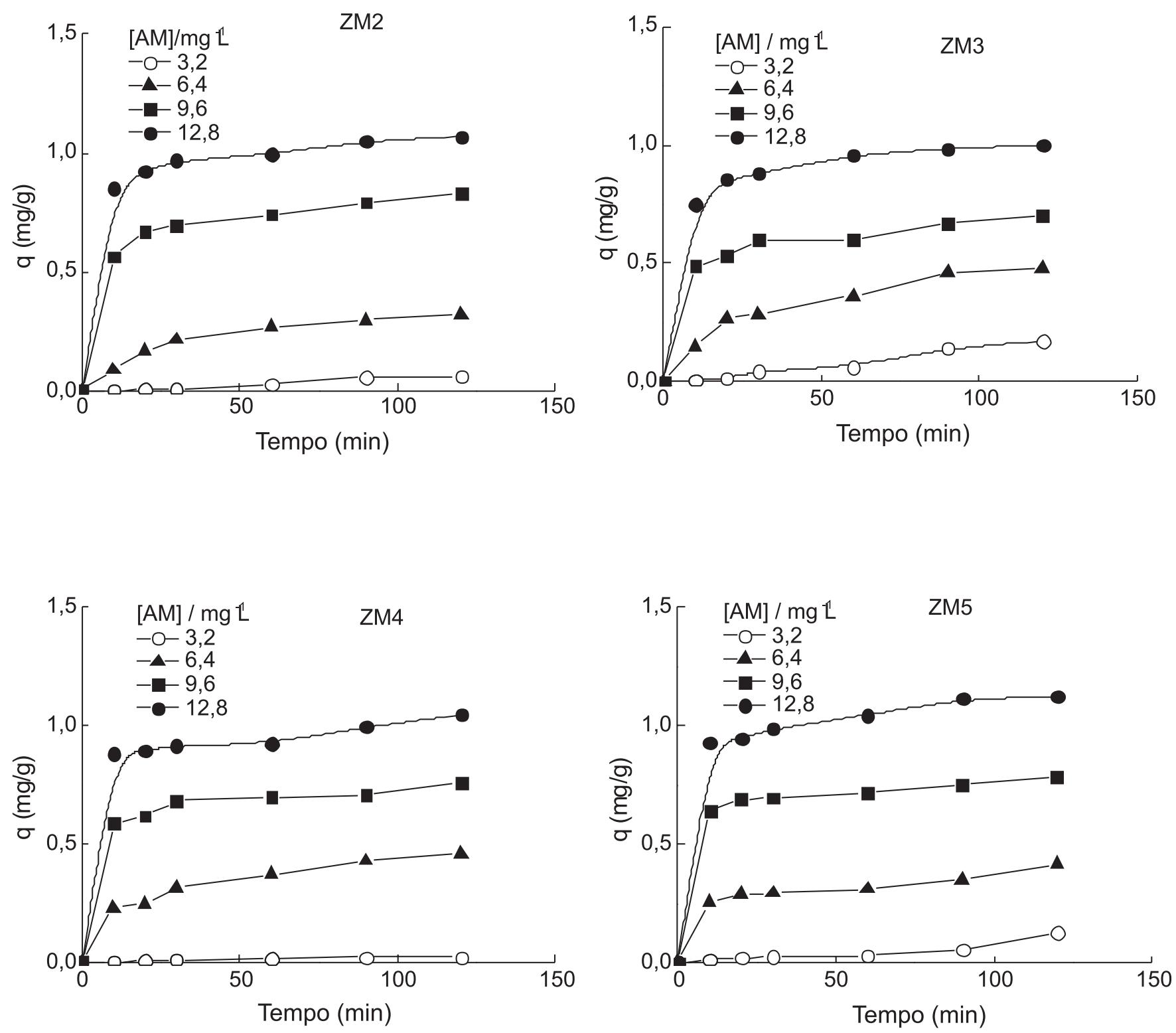

Figura 2S. Efeito do tempo de agitação e da concentração do azul de metileno sobre a capacidade de adsorção das zeólitas de cinzas de carvão ZM2 a ZM5 

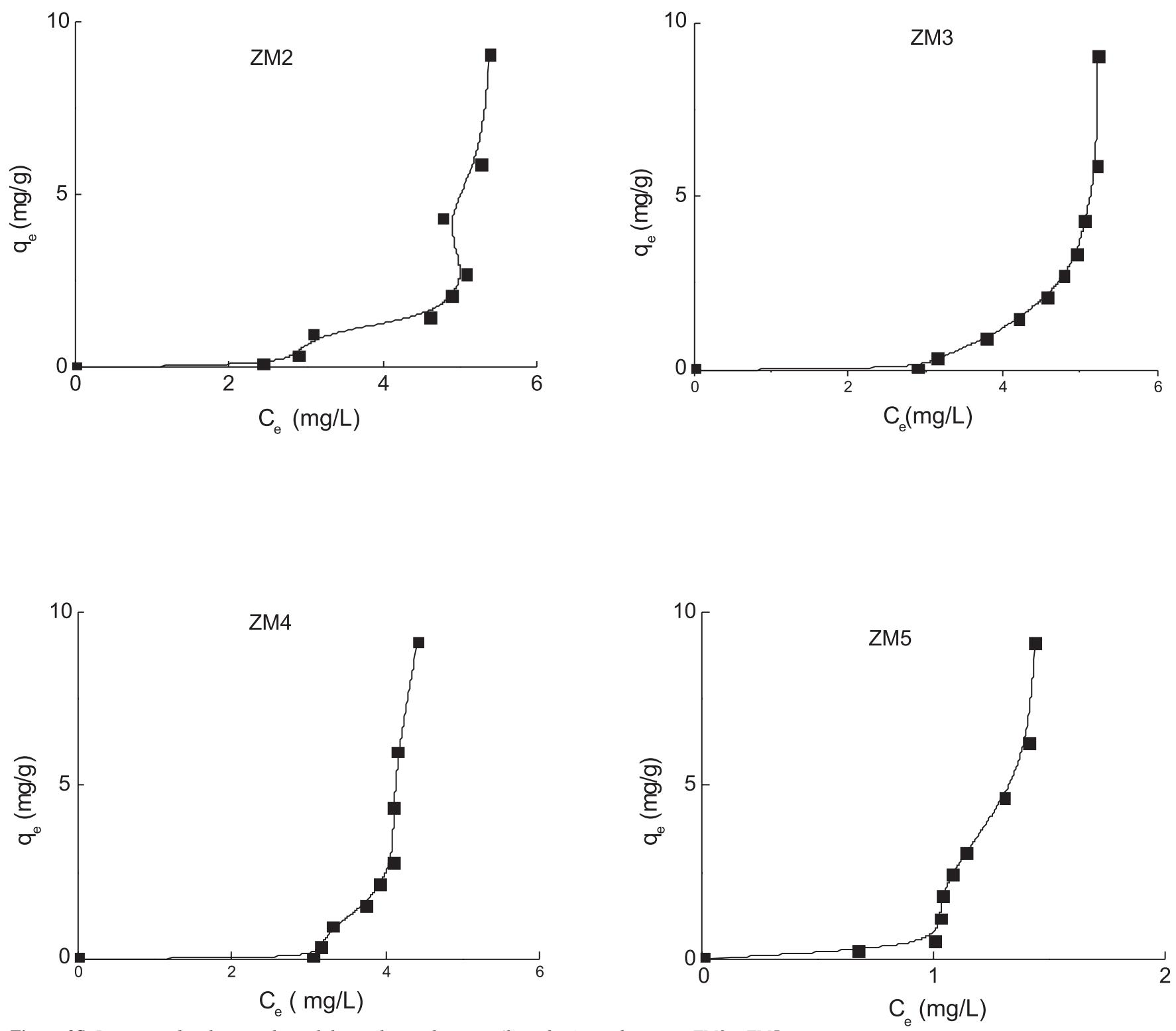

Figura 3S. Isotermas de adsorção do azul de metileno sobre as zeólitas de cinzas de carvão ZM2 a ZM5 